\title{
Role of immunosuppressive therapy and predictors of therapeutic effectiveness and renal outcome in IgA nephropathy with proteinuria
}

\author{
Yiping Ruan ${ }^{1,2}$, Wenfang Chen ${ }^{3}$, Zhibin $\mathrm{Li}^{4}$, Xueqing Tang ${ }^{1,2}$, Jianbo $\mathrm{Li}^{1,2}$, Xueqing $\mathrm{Yu}^{1,2}$, \\ Qiongqiong Yang ${ }^{1,2}$
}

\author{
${ }^{1}$ Department of Nephrology, The First Affiliated Hospital, Sun Yat-sen University, \\ Guangzhou, China \\ ${ }^{2}$ Key Laboratory of Nephrology, Ministry of Health, Guangzhou, Guangdong, China \\ ${ }^{3}$ Department of Pathology, The First Affiliated Hospital, Sun Yat-sen University, \\ Guangzhou, China \\ ${ }^{4}$ Epidemiology and Clinical Research Unit, The First Affiliated Hospital, Sun Yat-sen \\ University, Guangzhou, China
}

Submitted: 20 March 2013

Accepted: 10 May 2013

Arch Med Sci 2015; 11, 2: 332-339

DOI: 10.5114 /aoms.2015.50965

Copyright (c) 2015 Termedia \& Banach

\begin{abstract}
Introduction: The aim of the study was to analyze the role of immunosuppressive therapy and identify independent predictors of therapeutic effectiveness and outcome in IgA nephropathy (IgAN) patients with proteinuria. Material and methods: Two hundred and six IgAN patients with proteinuria (1-3.5 g/day) were included between January 2005 and December 2011, and divided into two groups: group $A(n=125)$, receiving renin-angiotensin system blockade therapy alone; and group B $(n=81)$, combining the above with immunosuppressive therapy. The clinicopathological features, response and safety were recorded. In univariate and multivariate models, the factors that influence response to therapy and renal outcome, especially pathologic features, were analyzed.

Results: The patients in group B presented more severe proteinuria and hypoalbuminemia with more severe hematuria $(p<0.05)$ but no significant difference in the pathologic changes compared with group A. After follow-up, the response rate was higher in group $B$ than in group $A(p<0.001)$. No pathologic feature or clinical parameter apart from steroid therapy $(\mathrm{HR}=$ $0.500,95 \% \mathrm{Cl}: 0.304-0.821, p=0.006)$ was strongly associated with therapeutic effectiveness. Endocapillary hypercellularity $(\mathrm{HR}=2.849,95 \% \mathrm{Cl}$ : 1.244-6.524, $p=0.013$ ) seemed to be an independent predictor of poor response to steroid therapy. The renal survival rate was not significantly different between the two groups $(p=0.074)$. Estimated glomerular filtration rate at baseline may be an independent predictor of renal outcome.

Conclusions: Steroid therapy could be an effective therapy in proteinuric IgAN patients, and endocapillary hypercellularity seemed to predict poor response to steroid. Renal function at baseline rather than treatment strategies and pathologic features may be independently associated with renal survival.
\end{abstract}

Key words: IgA nephropathy, outcome, predictor, proteinuria, therapy.

\section{Introduction}

IgA nephropathy (IgAN) is characterized by the predominant deposition of IgA in the glomerular mesangium, which is the most common

\author{
Corresponding author: \\ Prof. Qiongqiong Yang \\ Department of Nephrology \\ The First Affiliated Hospital \\ Sun Yat-sen University \\ 58 Zhongshan Road II \\ Guangzhou, 510080, China \\ Phone: 0086208766335 \\ Fax: 00862087769673 \\ E-mail:1722203886@qq.com
}


form of glomerulonephritis worldwide and accounts for nearly half of the primary glomerular diseases in China [1, 2]. End-stage renal disease (ESRD) occurs in approximately $15 \%$ of patients with IgAN within 10 years [3]. In the last few decades, some histologic classifications for IgAN have been developed $[4,5]$. Recently, the Oxford classification, a new histopathologic classification of IgAN, was developed by the International IgA Nephropathy Network [6, 7]. The classification was established according to the biopsies of 265 adults and children and consisted of four histopathologic features-mesangial hypercellularity $(M)$, endocapillary hypercellularity (E), segmental glomerulosclerosis (S) and tubular atrophy/interstitial fibrosis $(T)$. The purpose of this classification was to be reliable and simple for predicting clinical outcome, although it required validation in different populations [8]. Some medications, including angiotensin-converting enzyme (ACE) inhibitors and angiotensin receptor blocker (ARB), even steroids and immunosuppressants, were gradually used for treatment of glomerulonephritis such as proteinuric IgAN $[9,10]$. However, few therapeutic trials included pathologic factors and intended to find clinicopathological predictors. Only a small number of reports published different conclusions relative to the predictive value of the pathologic lesion on the therapeutic effectiveness and prognosis in IgAN patients [11-13].

In this single-center, retrospective study, we aimed to analyze the role of immunosuppressive therapy and identify the independent predictors, especially the predictive value of the pathological features for therapeutic effectiveness and renal survival in a cohort of patients with IgAN from southern China.

\section{Material and methods}

\section{Patient selection}

Patients with biopsy-proven IgAN with proteinuria (1-3.5 g/day) from 2005 to 2011, who were registered in the Sun Yat-sen University First Hospital IgAN Database (http://igan.medidata.cn), were enrolled in this study. Patients who met the following criteria were excluded: fewer than eight glomeruli on the biopsy; and secondary causes of mesangial IgA deposits, such as Henoch-Schonlein purpura, liver disease and systemic lupus erythematosus.

\section{Clinicopathologic data}

The following clinical and laboratory data were collected at the time of biopsy: age, gender, medical history, systolic and diastolic blood pressure, body mass index (BMI), serum cholesterol, triglycerides, high-density lipoprotein cholester- ol (HDL-C), low-density lipoprotein cholesterol (LDL-C), serum creatinine, blood urea nitrogen (BUN), serum albumin, uric acid, hemoglobin, amount of red blood cell (RBC) in urine and proteinuria, serum IgA and treatment modalities. Information such as proteinuria and serum creatinine was collected during the follow-up period. Drug safety was also recorded.

All renal biopsy specimens were divided routinely for immunofluorescence microscopy, light microscopy and electron microscopy. The paraffin-embedded sections were stained with hematoxylin and eosin, periodic acid-Schiff, silver methenamine, and Masson's trichrome. Two pathologists independently reviewed all renal biopsies and reached a consensus, according to the Oxford and Lee's classifications [6, 7]. Four pathologic features of the Oxford classification were defined as follows: mesangial score of $\leq 0.5(\mathrm{MO})$ or $>0.5$ (M1); segmental glomerulosclerosis absent (S0) or present (S1); endocapillary hypercellularity absent (E0) or present (E1); and tubular atrophy atrophy/interstitial fibrosis $\leq 25 \%$ (T0), 26-50\% (T1) or $>50 \%$ (T2).

\section{Definitions}

The time of renal biopsy was used as the starting point, and the study end point was defined as ESRD or doubling of creatinine level. End-stage renal disease was defined as an estimated glomerular filtration rate (eGFR) of $<15 \mathrm{ml} / \mathrm{min}$ per $1.73 \mathrm{~m}^{2}$, using the modified Modification of Diet in Renal Disease equation for the Chinese population or initiation of dialysis or transplantation [14]. Hypertension referred to a blood pressure of greater than 140/90 mm Hg; blood pressure measurements were repeated twice in a patient in a standing position and in the patient's right arm. The mean arterial pressure (MAP) was defined as a diastolic pressure plus one-third of the pulse pressure. Proteinuria was measured by 24-h urine protein collection. The average proteinuria every 6 months was calculated, which represented the time-averaged proteinuria. Renin-angiotensin system (RAS) blockade included exposure to angiotensin-converting enzyme inhibitor (ACEI), ARB, or both. Immunosuppressive therapy was defined as receiving steroids with or without an immunosuppressant. Steroid therapy included use of oral prednisone (starting at $1.0 \mathrm{mg} / \mathrm{kg}$ per day for 6 to 8 weeks and then tapered to 5 to $10 \mathrm{mg}$ every 2 weeks) for 6 months at least. Immunosuppressants included cyclophosphamide (used at a total dosage of 6 to $8 \mathrm{~g}$ ) or mycophenolate mofetil (used at a dosage of 1.5-2.0 g/day for 12 months). Response was defined as $\geq 50 \%$ reduction in proteinuria during follow-up, with stable renal function (serum creatinine within the normal range or 
not increased by $30 \%$ more than baseline values). Non-response was defined as $<50 \%$ reduction in baseline proteinuria or progression to renal survival end point (ESRD or doubling of creatinine level).

\section{Statistical analysis}

Continuous variables were expressed as the means \pm standard deviation or medians with the $25^{\text {th }}$ and $75^{\text {th }}$ percentiles and analyzed by the $t$ test or Mann-Whitney U-test. Categorical variables were presented as frequency with percentages and analyzed using the $\chi^{2}$ test. The occurrence of response and renal survival end point were analyzed using the Kaplan-Meier method compared by the log rank test. Univariate followed by multivariate Cox regression was used to determine the independent predictors of therapeutic effectiveness and renal survival during follow-up. All pathologic features were included in univariate Cox regression, and only pathologic features significantly associated with therapeutic effectiveness or renal survival were considered in multivariate Cox regression. The results were expressed as the hazard ratio (HR) with $95 \%$ confidence intervals (Cls). Value of $p<0.05$ was considered statistically significant. All statistical analyses were performed with SPSS 16.0 (SPSS Inc., Chicago, IL, USA).

\section{Results}

\section{Clinicopathologic characteristics of patients receiving immunosuppressive therapy}

The study population included 206 patients with average age of $33.2 \pm 10.1$ years at the time of biopsy. Mean MAP was $93.5 \pm 13.6 \mathrm{~mm} \mathrm{Hg}$, mean proteinuria was $1.7 \pm 0.6 \mathrm{~g} /$ day, and mean eGFR was $88.4 \pm 41.2 \mathrm{ml} / \mathrm{min}$ per $1.73 \mathrm{~m}^{2}$. According to the Kidney Disease Outcomes Quality Initiative classification, 94 (45.6\%), 56 (27.2\%), 43 (20.9\%) and 13 (6.3\%) patients had stages 1, 2, 3 and 4 chronic kidney disease, respectively. All patients received RAS blockade. One hundred and twenty-five patients received RAS blockade alone (60.7\%, 125/206); 81 patients $(39.3 \%, 81 / 206)$ received steroids, in 25 of them $(12.1 \%, 25 / 206)$ in combination with immunosuppressants (20 patients received mycophenolate mofetil and $5 \mathrm{pa}$ tients received cyclophosphamide).

The patients were divided into two groups according to different therapies, namely, RAS blockade therapy alone (group A) and in combination with immunosuppressive therapy (group B). At the time of renal biopsy, patients in group B presented with higher proteinuria (group B $2.0 \pm 0.7 \mathrm{~g}$ /day vs. group $A 1.6 \pm 0.5 \mathrm{~g} /$ day, $p<0.001$ ) and lower serum albumin (group B $35.8 \pm 5.7 \mathrm{~g} / \mathrm{l}$ vs. group A 38.3 $\pm 4.3 \mathrm{~g} / \mathrm{l}, p=0.001$ ) than patients in group $\mathrm{A}$. The severity of microscopic hematuria in group $B$ was mainly $\geq 2+$ (group B $44.4 \%$ vs. group A $24.8 \%$, $p=0.003)$. The time-averaged proteinuria was significantly higher in group B (group B $1.3 \pm 0.7 \mathrm{~g} /$ day vs. group A $1.1 \pm 0.7 \mathrm{~g} /$ day, $p=0.014$ ). Except for these, neither the laboratory indices nor the remaining clinical indices were significantly different between the two groups (Table I). There were no differences in any pathologic features (Table II).

\section{Response to therapy and renal outcome}

The follow-up period for these 206 patients was $28 \pm 16$ months, which showed no significant difference between the two groups (group B $29 \pm 14$ months vs. group A $27 \pm 16$ months, $p=0.339$ ).

Response rates in group $A$ at 1,2 and 3 years were $56.7 \%, 40.9 \%$ and $29.5 \%$, respectively. However, response rates in group B at 1, 2 and 3 years were $90.2 \%, 66.0 \%$ and $49.1 \%$, respectively; these rates were significantly higher than those in group $A$. It was suggested that immunosuppressant therapy may have a positive effect for therapeutic effectiveness in group $B$ in the follow-up.

The 3-year renal survival rate was not significantly different between the two groups (group B $91.6 \%$ vs. group A $84.7 \%, p=0.074$ ) (Figure 1 ). No death was reported in either group. Doubling of serum creatinine or ESRD occurred in 16 patients (7.8\% of all patients): 13 (10.4\%) in group A and $3(3.7 \%)$ in group B.

\section{Additional treatments}

Nine patients in group A (RAS blockade alone) received steroid therapy additionally after 18 to 33 months of follow-up because of relapsed proteinuria (1.9 to $3.4 \mathrm{~g} /$ day). Proteinuria again decreased in all cases (data not listed).

\section{Safety}

The side effects of the treatment were mild in both groups. None of the patients in either group developed intolerable cough or hyperkalemia that would cause withdrawal from RAS blockade treatment. One patient treated with steroids and 1 patient treated with steroids and mycophenolate mofetil experienced a common cold that was controlled quickly after symptomatic treatment. None of the patients who received immunosuppressive therapy developed diabetes mellitus. Serious adverse events such as serious infections were not observed in either group.

\section{Predictors of therapeutic effectiveness and renal outcome in proteinuric IgA nephropathy}

The impact of clinicopathological parameters and treatment scheme on the therapeutic effec- 
Role of immunosuppressive therapy and predictors of therapeutic effectiveness and renal outcome in IgA nephropathy with proteinuria

Table I. Clinical characteristics of IgA nephropathy patients treated with or without immunosuppressive therapy

\begin{tabular}{|c|c|c|c|c|}
\hline Parameter & $\begin{array}{c}\text { Total } \\
(n=206)\end{array}$ & $\begin{array}{l}\text { Group A } \\
(n=125)\end{array}$ & $\begin{array}{l}\text { Group B } \\
(n=81)\end{array}$ & Value of $p^{a}$ \\
\hline Age, mean \pm SD [years] & $33.2 \pm 10.1$ & $33.4 \pm 9.7$ & $33.0 \pm 10.7$ & 0.794 \\
\hline Male, $n(\%)$ & $86(41.7)$ & $54(43.2)$ & $32(39.5)$ & 0.599 \\
\hline $\begin{array}{l}\text { Interval between presentation } \\
\text { and biopsy [months] }\end{array}$ & $5(1,12)$ & $3(1,13)$ & $5(1,9)$ & 0.881 \\
\hline Tonsillitis, $n$ (\%) & $12(5.8)$ & $6(4.8)$ & $6(7.4)$ & 0.435 \\
\hline Hypertension, $n$ (\%) & $52(25.2)$ & $31(24.8)$ & $21(25.9)$ & 0.856 \\
\hline Systolic BP, mean \pm SD [mm Hg] & $122.6 \pm 16.8$ & $122.1 \pm 17.1$ & $123.4 \pm 16.5$ & 0.604 \\
\hline Diastolic BP, mean \pm SD [mm Hg] & $78.9 \pm 13.0$ & $78.9 \pm 13.0$ & $78.9 \pm 13.0$ & 0.999 \\
\hline MAP, mean $\pm S D[m m ~ H g]$ & $93.5 \pm 13.6$ & $93.3 \pm 13.7$ & $93.7 \pm 13.5$ & 0.812 \\
\hline BMI, mean $\pm \mathrm{SD}\left[\mathrm{kg} / \mathrm{m}^{2}\right]$ & $21.8 \pm 3.2$ & $22.0 \pm 3.2$ & $21.6 \pm 3.2$ & 0.405 \\
\hline Proteinuria, mean \pm SD [g/day] & $1.7 \pm 0.6$ & $1.6 \pm 0.5$ & $2.0 \pm 0.7$ & $<0.001$ \\
\hline Serum albumin, mean \pm SD $[\mathrm{g} / \mathrm{l}]$ & $37.3 \pm 5.0$ & $38.3 \pm 4.3$ & $35.8 \pm 5.7$ & 0.001 \\
\hline Cholesterol, mean \pm SD $[\mathrm{mmol} / \mathrm{l}]$ & $5.6 \pm 1.4$ & $5.5 \pm 1.3$ & $5.8 \pm 1.6$ & 0.129 \\
\hline Triglycerides, mean \pm SD $[\mathrm{mmol} / \mathrm{l}]$ & $1.7 \pm 1.2$ & $1.7 \pm 1.2$ & $1.7 \pm 1.1$ & 0.881 \\
\hline $\mathrm{HDL}-\mathrm{C}$, mean $\pm \mathrm{SD}[\mathrm{mmol} / \mathrm{l}]$ & $1.3 \pm 0.4$ & $1.2 \pm 0.3$ & $1.4 \pm 0.5$ & 0.055 \\
\hline LDL-C, mean $\pm \mathrm{SD}[\mathrm{mmol} / \mathrm{l}]$ & $3.5 \pm 1.2$ & $3.4 \pm 1.1$ & $3.6 \pm 1.3$ & 0.152 \\
\hline Serum creatinine, mean \pm SD $[\mu \mathrm{mol} / \mathrm{l}]$ & $102.9 \pm 53.6$ & $100.0 \pm 51.6$ & $107.4 \pm 56.5$ & 0.329 \\
\hline Serum creatinine $>133 \mu \mathrm{mol} / \mathrm{l}, n(\%)$ & $42(20.4)$ & $23(18.4)$ & $19(23.5)$ & 0.379 \\
\hline $\mathrm{eGFR}$, mean $\pm \mathrm{SD}\left[\mathrm{ml} / \mathrm{min} / 1.73 \mathrm{~m}^{2}\right]$ & $88.4 \pm 41.2$ & $92.2 \pm 43.5$ & $82.6 \pm 36.8$ & 0.100 \\
\hline BUN, mean \pm SD $[\mathrm{mmol} / \mathrm{l}]$ & $6.3 \pm 2.9$ & $6.2 \pm 2.9$ & $6.5 \pm 3.0$ & 0.508 \\
\hline Uric acid, mean \pm SD $[\mu \mathrm{mol} / \mathrm{l}]$ & $373.0 \pm 112.3$ & $370.9 \pm 112.4$ & $376.4 \pm 112.8$ & 0.734 \\
\hline Hemoglobin, mean $\pm \mathrm{SD}[\mathrm{g} / \mathrm{l}]$ & $126.1 \pm 18.4$ & $127.7 \pm 18.7$ & $123.6 \pm 17.9$ & 0.122 \\
\hline $\mathrm{RBC}$ in urine $\geq 2+, n(\%)$ & $67(32.5)$ & $31(24.8)$ & $36(44.4)$ & 0.003 \\
\hline Serum IgA, mean \pm SD $[g / l]$ & $3.0 \pm 0.9$ & $3.0 \pm 0.9$ & $3.0 \pm 0.9$ & 0.912 \\
\hline \multicolumn{5}{|l|}{ Follow-up: } \\
\hline Length of follow-up, mean \pm SD [months] & $28 \pm 16$ & $27 \pm 16$ & $29 \pm 14$ & 0.339 \\
\hline Time-averaged proteinuria, mean \pm SD [g/day] & $1.2 \pm 0.7$ & $1.1 \pm 0.7$ & $1.3 \pm 0.7$ & 0.014 \\
\hline \multicolumn{5}{|l|}{ Time-averaged proteinuria, $n(\%)$ : } \\
\hline$\leq 0.3$ & $6(2.9)$ & $6(4.8)$ & $0(0)$ & 0.022 \\
\hline $0.3-1.0$ & $100(48.5)$ & $68(54.4)$ & $32(39.5)$ & \\
\hline $1.0-2.0$ & $70(34.0)$ & $34(27.2)$ & $36(44.4)$ & \\
\hline $2.0-3.0$ & $27(13.1)$ & $16(12.8)$ & $11(13.6)$ & \\
\hline$\geq 3.0$ & $3(1.5)$ & $1(0.8)$ & $2(2.5)$ & \\
\hline Response, $n(\%)$ & $98(47.6)$ & $47(37.6)$ & $51(63.0)$ & $<0.001$ \\
\hline ESRD or doubling serum creatinine, $n$ (\%) & $16(7.8)$ & $13(10.4)$ & $3(3.7)$ & 0.079 \\
\hline
\end{tabular}

aValue of $p$ - comparison between group $A$ and group B. Value of $p<0.05$ was considered significant. BP - blood pressure, MAP - mean arterial pressure, $B M I$ - body mass index, HDL-C - high-density lipoprotein cholesterol, $L D L-C$ - low-density lipoprotein cholesterol, eGFR estimated glomerular filtration rate, $B U N$ - blood urea nitrogen, $R B C$ - red blood cell, ESRD - end-stage renal disease. 
Table II. Pathologic features of IgA nephropathy patients treated with or without immunosuppressive therapy at the time of biopsy

\begin{tabular}{|c|c|c|c|}
\hline Parameter & $\begin{array}{c}\text { Group } \mathrm{A}(N=125) \\
n(\%)\end{array}$ & $\begin{array}{c}\text { Group B }(N=81) \\
n(\%)\end{array}$ & Value of $p^{\mathrm{a}}$ \\
\hline Global glomerulosclerosis & $110(88.0)$ & $67(82.7)$ & 0.287 \\
\hline Segmental adhesion & $88(70.4)$ & $52(64.2)$ & 0.351 \\
\hline Crescents & $67(53.6)$ & $47(58.0)$ & 0.533 \\
\hline Mesangial hypercellularity MO/M1 & $61(48.8) / 64(51.2)$ & $37(45.7) / 44(54.3)$ & 0.661 \\
\hline Endocapillary hypercellularity E0/E1 & $92(73.6) / 33(26.4)$ & $50(61.7) / 31(38.3)$ & 0.072 \\
\hline Segmental glomerulosclerosis SO/S1 & $50(40.0) / 75(60.0)$ & $35(43.2) / 46(56.8)$ & 0.648 \\
\hline Tubular atrophy/interstitial fibrosis T0/T1-2 & $93(74.4) / 32(25.6)$ & $51(63.0) / 30(37.0)$ & 0.080 \\
\hline \multicolumn{4}{|l|}{ Lymphocyte and monocyte infiltration [\%]: } \\
\hline $0-25$ & $101(80.8)$ & $59(72.8)$ & \multirow[t]{2}{*}{0.180} \\
\hline$>25$ & $24(19.2)$ & $22(27.2)$ & \\
\hline Arteriolar wall thickening & $70(56.0)$ & $36(44.4)$ & 0.105 \\
\hline Arteriolar hyaline degeneration & $49(39.2)$ & $27(33.3)$ & 0.394 \\
\hline \multicolumn{4}{|l|}{ IgA glomerulus immunofluorescence: } \\
\hline$+1++$ & $80(64.0)$ & $53(65.4)$ & \multirow[t]{2}{*}{0.834} \\
\hline$+++/++++$ & $45(36.0)$ & $28(34.6)$ & \\
\hline \multicolumn{4}{|l|}{ Lee's classification: } \\
\hline II & $6(4.8)$ & $7(8.6)$ & \multirow[t]{3}{*}{0.399} \\
\hline III & $68(54.4)$ & 38 (46.9) & \\
\hline IV & $51(40.8)$ & $36(44.4)$ & \\
\hline
\end{tabular}

a $P$ value: comparison between group $A$ and group B. Value $p<0.05$ was considered significant.

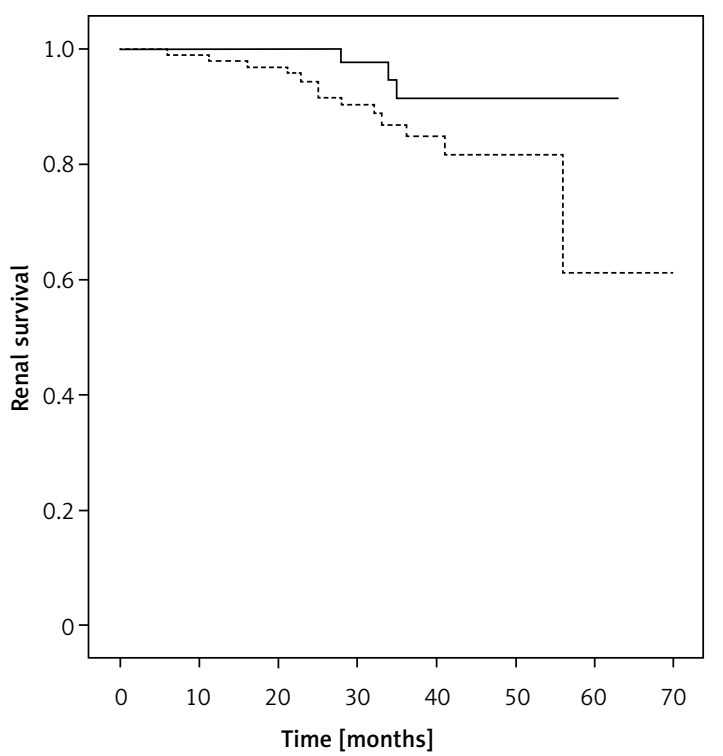

No. at risk

$\begin{array}{llllllll}\text { Group A } 125 & 99 & 78 & 57 & 27 & 7 & 3 & 0\end{array}$ $\begin{array}{llllllll}\text { Group B } & 81 & 74 & 56 & 37 & 20 & 6 & 2\end{array}$

..-'? Group A (RAS blockade)

$\neg$ Group B (RAS blockade + immunosuppressive therapy)

Figure 1. Kaplan-Meier renal survival for patients with IgA nephropathy treated with renin-angiotensin system (RAS) blockade therapy alone and in combination with immunosuppressive therapy. Log rank significance for ESRD or doubling creatinine $=0.074$ tiveness were analyzed. In univariate Cox analyses, no pathologic feature except steroid therapy $(p<0.001)$ and proteinuria $(p=0.015)$ was found to impact response to treatment. In multivariate Cox analyses, steroid therapy ( $H R=0.500$, $95 \%$ Cl: 0.304-0.821, $p=0.006)$ was a protective factor for response to treatment (Table III). Furthermore, endocapillary hypercellularity was found to be associated with a worse response to steroid therapy independently $(H R=2.849,95 \%$ Cl: 1.244-6.524, $p=0.013$ ) (Table IV).

In univariate Cox analyses, global glomerulosclerosis $(p<0.001)$, tubular atrophy and interstitial fibrosis $(p<0.001)$, and lymphocyte and monocyte infiltration $(p<0.001)$ were strongly associated with renal survival. Clinical parameters, including MAP $(p<0.001)$ and eGFR $(p<$ 0.001 ), had a significant influence on renal survival. In multivariate Cox analyses, model A (only pathologic parameters were considered) suggested that global glomerulosclerosis $(\mathrm{HR}=$ $1.029,95 \% \mathrm{Cl}: 1.007-1.052, p=0.011)$ and tubular atrophy and interstitial fibrosis (HR $=7.427$, $95 \% \mathrm{Cl}: 1.135-48.617, p=0.036)$ may be independent predictors of renal survival. Nevertheless, after adjusting for clinical parameters and treatment schemes in model B, only eGFR at baseline $(\mathrm{HR}=0.940,95 \% \mathrm{Cl}: 0.901-0.980, p=0.004)$ was a predictor for doubling creatinine or end-stage 
Table III. Predictors of response to therapy by Cox regression

\begin{tabular}{|lcccccc|}
\hline Parameter & \multicolumn{3}{c}{ Univariate analysis } & \multicolumn{3}{c|}{ Multivariate analysis $^{\mathrm{a}}$} \\
\cline { 2 - 7 } & $\mathrm{HR}$ & $95 \% \mathrm{Cl}$ & Value of $p$ & $\mathrm{HR}$ & $95 \% \mathrm{Cl}$ & Value of $p$ \\
\hline Age [years] & 0.997 & $0.977-1.017$ & 0.755 & & & \\
\hline Male & 0.890 & $0.606-1.309$ & 0.554 & & & \\
\hline MAP [mm Hg] & 1.011 & $0.997-1.025$ & 0.118 & 1.018 & $1.002-1.034$ & 0.030 \\
\hline eGFR [ml/min/1.73 m²] & 1.002 & $0.997-1.007$ & 0.488 & 1.004 & $0.998-1.009$ & 0.201 \\
\hline Proteinuria [g/day] & 0.662 & $0.476-0.922$ & 0.015 & 0.750 & $0.536-1.049$ & 0.093 \\
\hline Treated with steroids & 0.446 & $0.292-0.682$ & $<0.001$ & 0.500 & $0.304-0.821$ & 0.006 \\
\hline Treated with immunosuppressant ${ }^{\mathrm{b}}$ & 0.507 & $0.256-1.004$ & 0.051 & 0.901 & $0.410-1.982$ & 0.796 \\
\hline
\end{tabular}

a Multivariate model: multivariate with initial eGFR, MAP, proteinuria and treatment. ${ }^{b} /$ mmunosuppressant referred to cyclophosphamide or mycophenolate mofetil. MAP - mean arterial pressure, eGFR - estimated glomerular filtration rate, $\mathrm{Cl}$ - confidence interval. Value of $p<0.05$ was considered significant.

Table IV. Predictors of the response to steroids in 81 patients by Cox regression

\begin{tabular}{|c|c|c|c|c|c|c|}
\hline \multirow[t]{2}{*}{ Parameter } & \multicolumn{3}{|c|}{ Univariate analysis } & \multicolumn{3}{|c|}{ Multivariate analysis $^{\mathrm{a}}$} \\
\hline & $\mathrm{HR}$ & $95 \% \mathrm{Cl}$ & Value of $p$ & $\mathrm{HR}$ & $95 \% \mathrm{Cl}$ & Value of $p$ \\
\hline Age [years] & 1.003 & $0.965-1.043$ & 0.877 & & & \\
\hline Male & 0.745 & $0.352-1.577$ & 0.442 & & & \\
\hline MAP [mm Hg] & 1.015 & $0.989-1.041$ & 0.261 & 1.009 & $0.978-1.041$ & 0.579 \\
\hline eGFR $\left[\mathrm{ml} / \mathrm{min} / 1.73 \mathrm{~m}^{2}\right]$ & 0.990 & $0.978-1.002$ & 0.091 & 0.997 & $0.980-1.013$ & 0.689 \\
\hline Proteinuria [g/day] & 1.037 & $0.625-1.720$ & 0.888 & 0.899 & $0.513-1.576$ & 0.709 \\
\hline Treated with immunosuppressant ${ }^{\mathrm{b}}$ & 0.827 & $0.378-1.808$ & 0.634 & 0.876 & $0.358-2.147$ & 0.772 \\
\hline Global glomerulosclerosis (\%) & 1.017 & $1.003-1.032$ & 0.020 & 1.013 & $0.991-1.035$ & 0.258 \\
\hline E1 & 2.342 & $1.099-4.994$ & 0.028 & 2.849 & $1.244-6.524$ & 0.013 \\
\hline
\end{tabular}

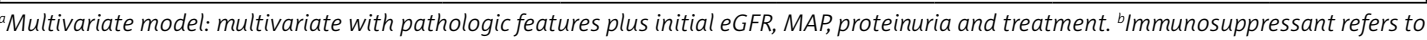
cyclophosphamide or mycophenolate mofetil. MAP - mean arterial pressure, eGFR - estimated glomerular filtration rate, Cl - confidence interval. Value of $p<0.05$ was considered significant.

renal disease; no pathologic feature had a significant influence (Table V).

\section{Discussion}

This study was designed to analyze the role of immunosuppressive therapy and identify independent predictors of therapeutic effectiveness and renal outcome in IgAN patients with proteinuria between 1 and $3.5 \mathrm{~g}$ /day who all received RAS blockade. We demonstrated that patients who received immunosuppressive therapy presented with more proteinuria, microscopic hematuria and hypoalbuminemia but similar pathologic lesions. Immunosuppressive therapy combined with RAS blockade, rather than RAS blockade therapy alone, was more effective in reduction of proteinuria but did not improve renal outcome, possibly because of the higher level of baseline proteinuria in group B. In addition, after adjusting for the influence of clinical parameters and immunosuppressants, steroid therapy may be an independent predictor for good response to treatment, and endocapillary hypercellularity seemed to be an independent predictor for poor response to steroid therapy. However, we observed that only eGFR at baseline can predict renal outcome independently of the pathologic features.

RAS blockade (ACEI and ARB) are widely used in the treatment of IgAN, because they eliminate two major progression factors (hypertension and proteinuria) and block the negative effects of angiotensin II in the kidney [15]. However, RAS blockade alone fails to achieve lowering of proteinuria in about $30-40 \%$ of patients [16]. Two small, randomized controlled trials from China $(n=63)$ and Italy $(n=97)$ suggested that compared with an ACEI alone, the addition of steroids to ACEI therapy provided more benefit in IgAN patients with proteinuria $>1 \mathrm{~g} /$ day $[17,18]$. Most other randomized controlled studies and systematic reviews indicated that steroid therapy, especially high-dose therapy, was associated with decreased protein- 
Table V. Predictors of renal survival by univariate and multivariate Cox regression without (model A) and with (model B) clinical parameters

\begin{tabular}{|c|c|c|c|c|c|c|c|c|c|}
\hline \multirow[t]{2}{*}{ Parameter } & \multicolumn{3}{|c|}{ Univariate analysis } & \multicolumn{3}{|c|}{ Multivariate model $\mathrm{A}^{\mathrm{a}}$} & \multicolumn{3}{|c|}{ Multivariate model $\mathrm{B}^{\mathrm{b}}$} \\
\hline & $H R$ & $95 \% \mathrm{Cl}$ & $\begin{array}{l}\text { Value } \\
\text { of } p\end{array}$ & $\mathrm{HR}$ & $95 \% \mathrm{Cl}$ & $\begin{array}{l}\text { Value } \\
\text { of } p\end{array}$ & $\mathrm{HR}$ & $95 \% \mathrm{Cl}$ & $\begin{array}{l}\text { Value } \\
\text { of } p\end{array}$ \\
\hline Age [years] & 1.029 & $\begin{array}{c}0.977- \\
1.083\end{array}$ & 0.283 & & & & & & \\
\hline Male & 0.391 & $\begin{array}{l}0.126- \\
1.214\end{array}$ & 0.104 & & & & & & \\
\hline $\mathrm{MAP}[\mathrm{mm} \mathrm{Hg}]$ & 1.068 & $\begin{array}{l}1.033- \\
1.103\end{array}$ & $<0.001$ & & & & 1.032 & $\begin{array}{c}0.989- \\
1.077\end{array}$ & 0.144 \\
\hline eGFR $\left[\mathrm{ml} / \mathrm{min} / 1.73 \mathrm{~m}^{2}\right]$ & 0.936 & $\begin{array}{l}0.910- \\
0.963\end{array}$ & $<0.001$ & & & & 0.940 & $\begin{array}{c}0.901- \\
0.980\end{array}$ & 0.004 \\
\hline Proteinuria [g/day] & 1.053 & $\begin{array}{l}0.481- \\
2.305\end{array}$ & 0.898 & & & & 0.797 & $\begin{array}{c}0.334- \\
1.899\end{array}$ & 0.609 \\
\hline Treated with steroids & 0.337 & $\begin{array}{c}0.096- \\
1.183\end{array}$ & 0.090 & & & & & & \\
\hline $\begin{array}{l}\text { Treated with } \\
\text { immunosuppressant }^{c}\end{array}$ & 0.395 & $\begin{array}{l}0.052- \\
2.992\end{array}$ & 0.369 & & & & & & \\
\hline $\begin{array}{l}\text { Global } \\
\text { glomerulosclerosis (\%) }\end{array}$ & 1.047 & $\begin{array}{l}1.030- \\
1.065\end{array}$ & $<0.001$ & 1.029 & $\begin{array}{l}1.007- \\
1.052\end{array}$ & 0.011 & 1.009 & $\begin{array}{c}0.981- \\
1.036\end{array}$ & 0.540 \\
\hline $\mathrm{T} 1-2$ & 18.699 & $\begin{array}{l}4.220- \\
82.864\end{array}$ & $<0.001$ & 7.427 & $\begin{array}{l}1.135- \\
48.617\end{array}$ & 0.036 & 1.309 & $\begin{array}{l}0.165- \\
10.385\end{array}$ & 0.799 \\
\hline $\begin{array}{l}\text { Lymphocyte and monocyte } \\
\text { infiltration }>25 \%\end{array}$ & 8.190 & $\begin{array}{l}2.821- \\
23.777\end{array}$ & $<0.001$ & 0.942 & $\begin{array}{c}0.254- \\
3.497\end{array}$ & 0.929 & 0.846 & $\begin{array}{l}0.212- \\
3.372\end{array}$ & 0.813 \\
\hline
\end{tabular}

a Multivariate model A: multivariate with pathologic features. ${ }^{b}$ Multivariate model B: multivariate with pathologic features plus initial eGFR, MAP and proteinuria. 'Immunosuppressant refers to cyclophosphamide or mycophenolate mofetil. MAP - mean arterial pressure, eGFR - estimated glomerular filtration rate, $\mathrm{Cl}$ - confidence interval. Value of $p<0.05$ was considered significant.

uria and reduced risk of ESRD [19-22]. Our study also showed that immunosuppressive therapy, especially steroid therapy, could have a greater effect on reduction of proteinuria in IgAN patients. Additionally, steroid therapy may be an independent factor for good reduction of proteinuria. Intriguingly, our subgroup analysis further revealed that endocapillary hypercellularity was a risk factor for poor response to steroid therapy. Endocapillary hypercellularity was found to be more common in patients who received immunosuppressive therapy and associated with response to steroids [6, 11, 23]; however, it was unknown whether endocapillary hypercellularity could be a predictor for therapeutic effectiveness independent of clinical and other pathologic features. So our result still needs to be confirmed by further studies.

Finally, we analyzed the predictors of renal outcome, especially the association between pathologic features and renal outcome, which has been a controversial topic before. Alamartine et al. analyzed 183 patients with IgAN with a mean follow-up duration of 6 years and denied the predictive value of the Oxford classification for renal outcome [13]. However, Zeng et al. demonstrated that mesangial hypercellularity and tubular atrophy/interstitial fibrosis lesions showed a similar predictive value regarding renal outcome in Chinese patients with IgAN, as presented in the Oxford cohort study $[6,11]$.
Shi et al. reported that segmental glomerulosclerosis and tubular atrophy/interstitial fibrosis were confirmed as predictive factors of ESRD independently of the clinical features and treatment; this finding was similar to a validation study from Japan [12, 24]. Recently, two studies from the United States and Korea showed that the degree of tubulointerstitial fibrosis was the only independent predictor of renal outcome $[25,26]$. In our study, only eGFR at baseline could be a better independent predictor for renal survival than pathologic features, including the Oxford classification, although when only considering pathologic features, glomerulosclerosis and tubular atrophy/interstitial fibrosis may be risk factors. The diverse conclusions about the pathological predictors of renal outcome might be associated with the following reasons. First, the study schemes in these studies were not the same. Some features, such as treatment, were not included in analyses. Second, these studies were retrospective studies in different centers; thus, distinguishing pathologic evaluation by pathologists and therapeutic strategies decided by clinicians might influence the results. Finally, patients enrolled in these studies had different clinical characteristics at baseline and came from different ethnic groups. Therefore, it is necessary to conduct larger sample size, prospective studies with a longer follow-up period to evaluate the pre- 
dictive value of pathologic features including the Oxford classification on the therapy effectiveness and renal survival in IgAN.

However, our study had several limitations. First, it was a retrospective study in a single center with a small sample size, which resulted in the non-uniform distribution of patient numbers between the two groups and might lead to some bias. For example, the therapy selection was decided by clinicians individually and tendentiously without uniform criteria, which may result in selection bias. The patients with more severe proteinuria were more likely to be treated with immunosuppressive therapy, which may make a difference in baseline proteinuria between the groups. As a result, renal outcome may be impacted even though proteinuria at baseline was adjusted. Second, the follow-up time was not long, so we may not discover a significant difference in the renal survival between the two groups; therefore, the long-term influence of immunosuppressive therapy on renal survival needs to be observed in longer follow-up. Thirdly, all patients received RAS blockade, so it was difficult to analyze its predictive value for therapy effectiveness and renal outcome. Furthermore, repeat biopsy was not performed to check the influence of treatment or disease deterioration on the kidney. All of these aspects need to be improved and perfected in future studies.

In conclusion, steroid therapy could be an effective therapy in proteinuric IgAN patients, and endocapillary hypercellularity seemed to predict poor response to steroid. Renal function at baseline rather than treatment strategies and pathologic features may be associated with renal survival independently.

\section{Conflict of interest}

The authors declare no conflict of interest.

\section{References}

1. Barratt J, Feehally J. IgA nephropathy. J Am Soc Nephrol 2005; 16: 2088-97.

2. Li LS, Liu ZH. Epidemiologic data of renal diseases from a single unit in China: analysis based on 13,519 renal biopsies. Kidney Int 2004; 66: 920-3.

3. D'Amico G. Natural history of idiopathic IgA nephropathy: role of clinical and histological prognostic factors. Am J Kidney Dis 2000; 36: 227-37.

4. Lee SM, Rao VM, Franklin WA, et al. IgA nephropathy: morphologic predictors of progressive renal disease. Hum Pathol 1982; 13: 314-22.

5. Haas M. Histologic subclassification of IgA nephropathy: a clinicopathologic study of 244 cases. Am J Kidney Dis 1997; 29: 829-42.

6. Cattran DC, Coppo R, Cook HT, et al. The Oxford classification of IgA nephropathy: rationale, clinicopathological correlations, and classification. Kidney Int 2009; 76: 534-45.
7. Roberts IS, Cook HT, Troyanov S, et al. The Oxford classification of IgA nephropathy: pathology definitions, correlations, and reproducibility. Kidney Int 2009; 76: 546-56.

8. Yamamoto R, Imai E. A novel classification for IgA nephropathy. Kidney Int 2009; 76: 477-80.

9. Floege J, Eitner F. Current therapy for IgA nephropathy. J Am Soc Nephrol 2011; 22: 1785-94.

10. Ostalska-Nowicka D, Malinska A, Silska M, Perek B, Zachwieja J, Nowicki M. Mycophenolate mofetil (MMF) treatment efficacy in children with primary and secondary glomerulonephritis. Arch Med Sci 2011; 7: 1042-8.

11. Zeng $\mathrm{CH}$, Le W, Ni Z, et al. A multicenter application and evaluation of the oxford classification of IgA nephropathy in adult chinese patients. Am J Kidney Dis 2012; 60: $812-20$

12. Shi SF, Wang SX, Jiang L, et al. Pathologic predictors of renal outcome and therapeutic efficacy in IgA nephropathy: validation of the oxford classification. Clin J Am Soc Nephrol 2011; 6: 2175-84.

13. Alamartine E, Sauron C, Laurent B, Sury A, Seffert A, Mariat C. The use of the Oxford classification of IgA nephropathy to predict renal survival. Clin J Am Soc Nephrol 2011; 6: 2384-8.

14. Ma YC, Zuo L, Chen JH, et al. Modified glomerular filtration rate estimating equation for Chinese patients with chronic kidney disease. J Am Soc Nephrol 2006; 17: 2937-44.

15. Boyd JK, Cheung CK, Molyneux K, Feehally J, Barratt J. An update on the pathogenesis and treatment of IgA nephropathy. Kidney Int 2012; 81: 833-43.

16. Coppo R, Feehally J, Glassock RJ. IgA nephropathy at two score and one. Kidney Int 2010; 77: 181-6.

17. Lv J, Zhang H, Chen Y, et al. Combination therapy of prednisone and ACE inhibitor versus ACE-inhibitor therapy alone in patients with IgA nephropathy: a randomized controlled trial. Am J Kidney Dis 2009; 53: 26-32.

18. Manno C, Torres DD, Rossini M, Pesce F, Schena FP. Randomized controlled clinical trial of corticosteroids plus ACE-inhibitors with long-term follow-up in proteinuric IgA nephropathy. Nephrol Dial Transplant 2009; 24: 3694-701.

19. Kim TY, Kim SB, Park SK. The efficacy of steroid pulse therapy in patients with IgA nephropathy. Clin Nephrol 2012; 78: 100-5.

20. Lv J, Xu D, Perkovic V, et al. Corticosteroid therapy in IgA nephropathy. J Am Soc Nephrol 2012; 23: 1108-16.

21. Zhou YH, Tang LG, Guo SL, et al. Steroids in the treatment of IgA nephropathy to the improvement of renal survival: a systematic review and meta-analysis. PLoS One 2011; 6: e18788.

22. Pozzi C, Andrulli S, Del VL, et al. Corticosteroid effectiveness in IgA nephropathy: long-term results of a randomized, controlled trial. J Am Soc Nephrol 2004; 15: 157-63.

23. Herzenberg AM, Fogo AB, Reich HN, et al. Validation of the Oxford classification of IgA nephropathy. Kidney Int 2011; 80: 310-7.

24. Katafuchi R, Ninomiya T, Nagata M, Mitsuiki K, Hirakata H. Validation study of oxford classification of IgA nephropathy: the significance of extracapillary proliferation. Clin J Am Soc Nephrol 2011; 6: 2806-13.

25. Yau T, Korbet SM, Schwartz MM, Cimbaluk DJ. The Oxford classification of IgA nephropathy: a retrospective analysis. Am J Nephrol 2011; 34: 435-44.

26. Kang SH, Choi SR, Park HS, et al. The Oxford classification as a predictor of prognosis in patients with IgA nephropathy. Nephrol Dial Transplant 2012; 27: 252-8. 